\title{
Developmental Changes in the Relation between Phosphate Metabolites and Oxygen Consumption in the Sheep Heart In Vivo
}

\author{
Michael A. Portman, F. W. Heineman, and Robert S. Balaban \\ With the technical assistance of Susan James \\ Laboratory of Cardiac Energetics, National Heart, Lung, and Blood Institute, Bethesda, Maryland 20892
}

\begin{abstract}
This study examines the role of phosphate metabolites in the regulation of mitochondrial oxygen consumption of the heart in vivo as a function of development. We used an open chest lamb/sheep preparation in which myocardial oxygen consumption $\left(\mathrm{MV}_{\mathrm{O}_{2}}\right)$ was monitored via an extracorporeal shunt from the coronary sinus. Phosphate metabolites were monitored simultaneously using ${ }^{31} \mathrm{P}$ nuclear magnetic resonance with a surface coil overlying the left ventricle. Graded infusions of epinephrine were used to increase $\mathrm{MV}_{\mathrm{O}_{2}}$ in both neonatal lambs (age 5-12 d, $n=8$ ), and mature sheep (26-86 d, $n=6$ ). The maximal increase in $\mathrm{MV}_{\mathrm{O}_{2}}$ achieved was $220 \pm 38 \%$ in the newborns and $350 \pm 66 \%$ in the mature animals. Associated with these increases in $\mathrm{MV}_{\mathrm{O}_{2}}$ in the newborn lambs are significant $(P<0.001)$ decreases in PCr/ATP, and increases in calculated ADP and intracellular $P_{i}$. This was in contrast to the mature sheep, in which there were no significant changes in PCr/ATP, ADP, or $P_{i}$. In conclusion, we find that $(a)$ there are changes in PCr/ATP, $P_{i}$, and ADP in newborn animals with moderate increases in work that are not apparent in mature animals of the same species and $(b)$ that these changes suggest that cytosolic ATP hydrolysis products may be more important in regulation of myocardial energy metabolism in the newborn than in the adult.
\end{abstract}

\section{Introduction}

Myocardial energy metabolism has been shown to change immediately after birth (1-3). Increases in resting myocardial oxygen consumption $\left(\mathrm{MV}_{\mathrm{O}_{2}}\right)^{1}$ occur during the transition from an intrauterine environment low in oxygen tension to the postpartum normoxic condition $(4,5)$. After this transition, there is a subsequent decrease in resting cardiac work and $\mathrm{MV}_{\mathrm{O}_{2}}$ as metabolic demands change from the newborn to adult state $(4,5)$. However, little information is available on changes in the regulation of mitochondrial respiration in vivo, which may occur as a function of development.

A preliminary report of this study was presented at the 1988 Annual Meeting of the Society for Pediatric Research.

Address reprint requests to Dr. Robert S. Balaban, Laboratory of Cardiac Energetics, National Heart, Lung, and Blood Institute, Building 1, Room SB15, National Institutes of Health, Bethesda, MD 20892. 1988.

Received for publication 8 June 1988 and in revised form 29 August

1. Abbreviations used in this paper: $\mathrm{MV}_{\mathrm{O}_{2}}$, myocardial oxygen consumption; NMR, nuclear magnetic resonance.

The Journal of Clinical Investigation, Inc.

Volume 83, February 1989, 456-464
Several mechanisms have been considered to regulate myocardial respiration under normal conditions. Studies from isolated mitochondria have long promulgated the theory that the ATP hydrolysis products, ADP and $\mathrm{P}_{\mathrm{i}}$, play the prominent role in regulating oxidative phosphorylation $(6,7)$. More recent studies performed on perfused and in vivo hearts have indicated that these metabolites are not as important as previously believed (8-11). Perfused heart studies have suggested that the mitochondrial NADH redox state or the mitochondrial membrane potential may be important factors $(8,11)$. Still other investigators have suggested that myocardial oxygen supply could be a primary determinant of the respiratory rate $(12,13)$.

Most investigations of mitochondrial respiratory control in fetal and neonatal heart have concentrated on the study of isolated mitochondria $(2,14-17)$. These studies have all found that the efficiency of the mitochondria or the ADP phosphorylated per oxygen consumed is the same throughout development $(2,14,16)$. However, a great deal of controversy exists with regard to the maximum ATP production rate of the individual mitochondrion $(2,14)$. In the most complete study to date, Wells et al. (14) showed that the maximum rate of ATP production per unit of cytochrome $a, a_{3}$ activity was not different through development. Differences noted between the fetus, neonate, and adult in some studies could be attributable to the amount of protein extracted during mitochondrial isolation and to the higher activity of cytochrome oxidase per gram wet weight in fetal hearts (15-17). Wells et al. also noted that the neonatal mitochondria had a lower resting ATP turnover rate per cytochrome $a, a_{3}$, resulting in a higher respiratory control ratio. However, this phenomenon, as pointed out by numerous investigators (18), is not a reliable measure of mitochondrial respiratory control in vivo.

The purpose of the present study was to investigate, in vivo, the relation between phosphate metabolite content and myocardial work and oxygen consumption in newborns and adults of the same species. To perform this experiment we have a developed a model using sheep, in which phosphate metabolites and myocardial oxygen consumption are simultaneously monitored (19).

\section{Methods}

Animal preparation. Mixed breed Western lambs from two separate age groups were used for this study. Neonatal lambs were 4-12 d old, (mean $7.9 \mathrm{~d}$ ), and weighed between 5 and $10 \mathrm{~kg}$. The size of mature sheep used in this study was dictated by the magnet's $26-\mathrm{cm}$ clear bore dimensions. Animals weighing $>20 \mathrm{~kg}$ were too large to fit into the 26-cm clear bore. Consequently, we used sheep, that were between 26 and $90 \mathrm{~d}$ old (mean $60 \mathrm{~d}$ ), and weighed 13-20 kg.

Initial sedation was performed by intramuscular injection of 10 $\mathrm{mg} / \mathrm{kg}$ ketamine and $0.2-0.4 \mathrm{mg} / \mathrm{kg}$ xylazine. The animals were then 
intubated and ventilated (with a D-900 pediatric ventilator; SiemensAllis, Inc., Cherry Hill, NJ) with an anesthesia mixture of $0.5-1.0 \%$ halothane and $\sim 99.0 \%$ oxygen. Femoral artery cannulation was performed for monitoring of systemic arterial blood pressure and blood sampling. Arterial blood $\mathrm{pH}$ was maintained between 7.35 and 7.45 by adjustment of the ventilatory tidal volume and correction of metabolic acidosis with intravenous sodium bicarbonate. Arterial $\mathrm{PO}_{2}$ was maintained in excess of $100 \mathrm{mmHg}$, whereas arterial $\mathrm{PCO}_{2}$ was kept between 35 and $45 \mathrm{mmHg}$. After stabilization of blood pressure and blood gas parameters, either a left thoracotomy or median sternotomy was performed. The pericardium overlying the left ventricle was exposed and its fat pad was removed.

Coronary sinus blood flow was measured via an extracorporeal shunt between the coronary sinus and the superior vena cava as previously described (19). This was fashioned by cannulating both jugular veins with heparin flushed tubing (Tygon, Norton Performance Phastics, Akron, $\mathrm{OH} ; 1 / 8$ in. i.d., $3 / 16$ in. o.d.). One end of the tube was advanced retrograde into the coronary sinus, while the other was positioned in the superior vena cava. A cannulating ultrasonic transit time probe (Transonic Systems, Inc., Ithaca, NY) was inserted in the tubing for continuous measurement of shunt flow, as was a $\mathrm{T}$ connector for sampling for $\mathrm{O}_{2}$ content. The sinus catheter tip was positioned between the coronary sinus orifice and the juncture of the great cardiac and hemiazygous veins. A suture was placed around the coronary sinus to anchor the tip and direct all coronary sinus drainage into the Tygon shunt. The hemiazygous vein was then ligated to prevent any systemic venous contribution to the shunt.

An ellipsoid-shaped nuclear magnetic resonance (NMR) surface coil $(3.5 \times 2 \mathrm{~cm})$ that conformed to the general shape of the lamb heart was then sutured to the pericardium overlying the left ventricle as near to the apex as possible. This type of coil attachment allowed unrestricted cardiac motion, while keeping the coil in reproducible proximity of the heart $(11,20)$. The thoracotomy opening was then sealed with plastic wrap to prevent water loss. Normal saline and dextrose solution was infused to maintain fluid homeostasis.

The lamb was wrapped in a water-circulating heating pad and a thermal insulating blanket (Boy Scouts of America, Bethesda, MD) to maintain core body temperature at $\sim 38^{\circ} \mathrm{C}$. The animal was then placed in a specially designed lucite cradle that allowed the centering of the heart in the $x$ and $y$ planes before placement into the magnet bore.

$N M R$ measurements. Just before transfer of the lamb into the 26-cm clear-bore magnet (Oxford Instruments, Oxford, England), the NMR surface coil was tuned to $81 \mathrm{MHz}$ and matched to $50 \Omega$ for detection of ${ }^{31} \mathrm{P}$ at $4.7 \mathrm{~T}$. Centering along the $z$ axis was performed using the imaging gradients by monitoring the ${ }^{1} \mathrm{H}$ signal in a gradientrecalled echo sequence. Ventilation was maintained in the magnet via 12 feet of Tygon tubing attached to the inspiratory and expiratory ports of the respirator. Blood pressure was monitored using a solid state nonmagnetic pressure transducer (Cobe Lab. Inc., Lakewood, CO), positioned just outside the magnet bore.

NMR data were collected with a General Electric (Fremont, CA) CSI spectrometer. Shimming on the ${ }^{1} \mathrm{H}$ free induction decay (at 200 $\mathrm{MHz}$ ) and acquisition of ${ }^{31} \mathrm{P}$ NMR spectra (at $81 \mathrm{MHz}$ ) were performed as described by Katz et al. (20). Respiratory gating for data acquisition for all experiments was performed by using the begin inspiratory reference pulse from the ventilator (D-900) to trigger the spectrometer. The respiratory rate in these studies was 30 breaths/min, which corresponded to an interpulse delay of $2 \mathrm{~s}$. The radio frequency excitation pulse width to obtain the maximum $\mathbf{P C r}{ }^{31} \mathrm{P}$ NMR signal from the heart was determined before each experiment and varied with lamb size from 20 to $35 \mu \mathrm{s}$ (with a 100-W power amplifier).

Spin lattice relaxation measurements. Before determination of spin-lattice relaxation times $\left(T_{1}\right)$, animals were paced to a precise harmonic of the respiratory rate to improve the magnetic field shimming around the heart (20). Pacing was accomplished using bipolar atrial leads that were implanted before transfer of the animal into the magnet. Lambs underwent $T_{1}$ measurements of the heart, either after completion of the epinephrine protocol with satisfactory recovery ( $n$
$=3$ ), or initially without undergoing any other protocol $(n=2)$. $T_{1}$ relaxation times were determined according to a previously described burst saturation technique (20), which used the following sequence: predelay- $60 \times\left(400 \mu \mathrm{s}^{\text {pulse }}{ }^{-1} \mathrm{~ms}\right.$ delay $)$-variable delay- $40 \mu \mathrm{s}$ pulseacquisition. The variable delay times were $16,8,3,1.5,0.8,0.6,0.4$, 0.2 , and $0.1 \mathrm{~s}$.

Epinephrine infusion protocol. To stimulate myocardial oxygen consumption, epinephrine was infused via central venous line in increasing dosage steps. The protocol began with a 10 -min baseline period, during which ${ }^{31} \mathrm{P}$ NMR data, systemic blood pressure, heart rate, and coronary blood flow were simultaneously recorded. After completion of the baseline period, epinephrine was infused for 10 -min periods at doses of $1,2,3$, and $4 \mu \mathrm{g} / \mathrm{kg}$ per min in neonatal lambs and $1,2,4$, and $8 \mu \mathrm{g} / \mathrm{kg}$ per min in mature lambs. Hemodynamic parameters, including coronary blood flow, were noted to stabilize at $\sim 2-4 \mathrm{~min}$ after beginning each epinephrine dose. Coronary sinus and arterial blood samples were therefore obtained simultaneously for determination of $\mathrm{O}_{2}\left(\mathrm{Lex}-\mathrm{O}_{2}-\mathrm{CON}\right)$ content at 6-7 min into each period. Myocardial oxygen consumption was calculated using the product of coronary blood flow times $\mathrm{O}_{2}$ extracted.

${ }^{31} \mathrm{P}$ NMR data were collected in 2-min blocks of 60 averaged acquisitions. The interpulse delay as determined by the respiratory cycle was $\sim 2 \mathrm{~s}$. The last four blocks or $8 \mathrm{~min}$ of each protocol period were averaged and analyzed as discussed in the Data Analysis section.

In our initial experiments, we found that sheep were unable to maintain an adequate blood pressure if the epinephrine infusion was terminated after completion of the protocol. This was presumably due to postcatecholamine depression, which has been well documented in lambs (21), and the predominance of beta receptor-mediated peripheral vasodilatation with decreasing epinephrine doses (22). To achieve a recovery phase the epinephrine dose was slowly reduced until the animal's hemodynamic parameters returned to near baseline levels. Titration of the epinephrine dose usually took $15-20 \mathrm{~min}$. Hemodynamic data and $10 \mathrm{~min}$ of NMR spectra were collected at the end of a 40-min period after completion of the initial protocol.

Analysis of ATP and total creatine. Measurement of ATP and total creatine concentrations was necessary for calculation of free cytosolic ADP concentrations. Left ventricular extracts for analysis of these metabolites were prepared using standard freeze clamping techniques as previously described (23). After thoracotomy, portions of the left ventricle were obtained from a beating heart either through direct freeze clamping of the apex with Wallenberg tongs (Instrument Shops, National Institutes of Health, Bethesda, MD), which had been immersed in liquid nitrogen, or via a drill biotome and immediately followed by freeze clamping. Samples were then rapidly immersed and pulverized under liquid nitrogen. They were then weighed and extracted with known quantities of $0.4 \mathrm{M}$ perchloric acid and neutralized with a phosphate-buffered $\mathrm{KOH}$ solution. Several hearts were rapidly excised and frozen in $100 \%$ ethanol chilled with dry ice. Samples from these hearts were extracted as above for analysis of total creatine only. The paired-ion reverse-phase HPLC methods of Juengling and Kammermeier (23) were used for the ATP and creatine analyses with a ion-exchange column (model 171252; Waters Associates, Milford, MA).

Data analysis. Coronary sinus blood flow and $\mathrm{MV}_{\mathrm{O}_{2}}$ were normalized to the left ventricular wet weight. This was determined by weighing the heart at the end of the experiment after excision of the atria and of the right ventricular free wall to the septal margin. $\mathrm{MV}_{\mathrm{O}_{2}}$ values are reported in micromoles per minute per gram wet weight of left ventricle.

Collection and averaging of ${ }^{31} \mathrm{P}$ NMR spectra were performed as described above. Resulting spectra were analyzed using the GEMCAP Lorentzian line-fitting program, which is a routine resident in the GEMCSI software. All NMR data were normalized to the beta phosphate ATP resonance in the control spectrum. Additionally, all peak areas were corrected for differential saturation determined from the $T_{1} S$ of individual spins, taking into account the inhomogeneity of the surface coil (24). Data from the burst saturation recovery experiments 
were used to generate exponential curves using a three-parameter fit routine resident in the GEMCSI program for calculation of the $T_{1} s$. Values for $T_{1} \pm$ SEM were: beta-ATP, $1.5 \pm 0.1 \mathrm{~s} ; \mathrm{PCr}, 4.1 \pm 0.2 \mathrm{~s}$, and the 2,3 DPG- $P_{i}$ resonance, $2.5 \pm 0.3 \mathrm{~s}$.

The low concentration of ADP in heart tissues prevents direct determination by either NMR or extraction techniques. ADP concentrations are estimated using the creatine kinase equilibrium reaction (25): $[\mathrm{ADP}]=[\mathrm{ATP}][\mathrm{Cr}] / K_{\mathrm{eq}}[\mathrm{PCr}]\left[\mathrm{H}^{+}\right]$.

Use of this approach requires knowledge of the tissue creatine $(\mathrm{Cr})$, phosphocreatine ( $\mathrm{PCr}$ ), and free magnesium concentrations, as well as the $\mathrm{pH}$ and the equilibrium constant $\left(K_{\mathrm{eq}}\right)$ of the reaction (26). The control ATP and total creatine concentrations were determined from the freeze-extraction data. Free intracellular magnesium levels (27) and $\mathrm{pH}(20)$ can be estimated using ${ }^{31} \mathrm{P}$ NMR data. The $K_{\mathrm{eq}}$ used was $1.66 \times 10^{9}$, as reported by Lawson and Veech (26) for conditions of $\mathrm{pH}$ $=7.0$ at $38^{\circ} \mathrm{C}$, and $\mathrm{Mg}^{2+}$ concentration of $1.0 \mathrm{mM} /$ liter. Note that the $K_{\text {eq }}$, according to that study, varies only minimally with changes in $\mathrm{Mg}^{2+}$ concentration in the physiologic range (1-3.6 mM), and $\mathrm{pH}$ values between 7.0 and $7.2(26)$. Assuming that the total creatine concentration does not change during the protocol, changes in free ADP concentration can be estimated from the equation given using the $\mathrm{T}_{1}$-corrected ${ }^{31} \mathrm{P}$ NMR data for PCr and ATP and the equation given. Because this is a multivariate analysis and there are minor deviations in these experiments from the experimental conditions established for the calculation of the $K_{\text {eq }}$, we can only consider this determination an estimate of the absolute free intracellular [ADP]. Note also that changes in the PCr/ATP should be inversely proportional to changes in the free ADP levels if $\mathrm{pH}$ and total creatine remain constant.

Analysis of changes in $P_{i}$ in the newborn animals was difficult due to interference from 2,3 diphosphoglycerate. The details of this problem are outlined in the Discussion.

Statistical analyses were performed using paired $t$ tests with each animal as its own control. PCr/ATP, calculated ADP, calculated $P_{i}$, the chemical shifts of $\mathrm{Mg}^{2+}$ and intracellular $P_{i}$, and myocardial oxygen extraction from each subsequent increase in $\mathrm{MV}_{\mathrm{O}_{2}}$ were compared with the baseline level. Unpaired $t$ tests between both groups of animals were performed for control parameters and maximum coronary blood flow. Linear regression analysis was used to analyze the relationship between $\mathrm{MV}_{\mathrm{O}_{2}}$ and the $\mathrm{PCr} / \mathrm{ATP}$ ratio in each animal group. A $t$ test was used to compare the slopes of the two lines derived from the linear regression analysis (28). All descriptive statistical data are reported with the SEM.

\section{Results}

Control physiologic parameters and relative concentrations of ${ }^{31} \mathrm{P}$ metabolites. The mean control values for both age groups are summarized in Table $\mathrm{I}$, along with results of the unpaired $t$ tests for each parameter between the two populations. Statistical significance in this table was defined at the $95 \%$ confidence level.

A ${ }^{31} \mathrm{P}$ spectrum from an animal from each group is presented in Fig. $1, A$ and $B$. Note that there is a significant contribution of 2,3 diphosphoglycerate (DPG) at 4.9 parts per million (ppm) in the newborn, but not in the mature animal. A ${ }^{31} \mathrm{P}$ NMR spectrum of newborn lamb blood is shown in Fig. 2. The chemical shifts of the 2,3 DPG in lamb blood are 4.86 and $5.93 \mathrm{ppm}$. The 2,3 DPG resonance at $4.86 \mathrm{ppm}$ will overlap with the expected intracellular $\mathrm{P}_{\mathrm{i}}$ signal at $4.9 \mathrm{ppm}\left(\mathrm{pH}_{\mathrm{i}}\right.$ $=7.10$ ). Thus, the interference between 2,3 DPG and intracellular $P_{i}$ is significant in this preparation and is further evaluated in the Discussion.

An additional observation is the prominence of the phosphomonoester peaks in the newborn (Fig. 1). This has also been noted during developmental comparisons of newborn and adult brains from rodents (29) and canines (30).
Table I. Average Control Values

\begin{tabular}{lccl}
\hline & Newborn (5-12 d) & Mature (26-90 d) & \multicolumn{1}{c}{$t$} \\
\hline$n$ & 8 & 6 & \\
Age & $7.9 \pm 1.0$ & $55.6 \pm 6.1$ & $P<0.001$ \\
$\mathrm{RPP}$ & $8,911 \pm 610$ & $7,015 \pm 740$ & $\mathrm{NS}$ \\
$\mathrm{MVO}_{2}$ & $2.30 \pm 0.23$ & $1.44 \pm 0.13$ & $P<0.05$ \\
$\mathrm{CBF}$ & $0.60 \pm 0.049$ & $0.42 \pm 0.033$ & $P<0.05$ \\
$\mathrm{PCr} / \mathrm{ATP}$ & $1.66 \pm 0.048$ & $1.68 \pm 0.097$ & $\mathrm{NS}$ \\
$\mathrm{pH}$ & $7.06 \pm .014$ & $7.10 \pm 0.026$ & $\mathrm{NS}$ \\
$\mathrm{ADP}$ (calc.) & $28 \pm 3.1$ & $28 \pm 5.1$ & $\mathrm{NS}$ \\
& & & \\
\hline
\end{tabular}

${ }^{31} \mathrm{P}$ NMR and hemodynamic data from newborn and mature lambs were monitored for a 10 -min control period before infusion with epinephrine. ADP, calculated ADP in micromoles/liter cell water (see text); CBF, coronary blood flow expressed as cubic centimeters/gram per minute; $\mathrm{MVO}_{2}$, expressed as micromoles/gram per minute; $\mathrm{PCr}$ / ATP, ratio of area of $\mathrm{PCr}$ peak/ $\beta$-ATP; $\mathrm{pH}_{\mathrm{i}}$, intracellular $\mathrm{pH}$ as determined by chemical shift of $P_{i}$; RPP, heart rate $\times$ mean systemic pressure (millimeters of mercury $\cdot$ beats per minute); $t$, result of unpaired $t$ test. Symbols are the same for subsequent tables unless otherwise noted.

Freeze clamp extraction data corrected for cell water content of $80 \%$ resulted in total creatine of $20.4 \pm 0.75 \mathrm{mM} /$ liter cell water $(n=6)$, and ATP concentration of $8.57 \pm 0.50 \mathrm{mM} /$ liter cell water $(n=3)$.

Table II presents hemodynamic and NMR data from two newborn animals who were monitored for a 1-h period without undergoing epinephrine infusion. These experiments were performed as supplemental time controls to evaluate the stability of the phosphate metabolites in this preparation. Of importance is that there are no changes in the PCr/ATP ratio $>3 \%$, which is within the error of the method.

Effects of epinephrine infusion in the newborn. Data obtained from the epinephrine infusion protocols are summarized in Table III for the newborn lamb group. Average maximum $\mathrm{MV}_{\mathrm{O}_{2}}$ was $220 \pm 38 \%$ over baseline. There were no significant changes in myocardial oxygen extraction. The ${ }^{31} \mathrm{P}$ NMR spectra from a representative experiment in a newborn are shown in Fig. 3, $A$ and $B$. As seen in these figures, there is only a small decrease in phosphocreatine and no relative change in $\mathrm{P}_{\mathrm{i}}$ with the initial step up in $\mathrm{MV}_{\mathrm{O}_{2}}$. However, a large change in $\mathrm{PCr}$ and an increase in $\mathrm{P}_{\mathrm{i}}$ are evident, as the heart is driven to a higher rate of oxygen consumption. Recovery spectra showed complete resolution of these changes (see Table III).

Paired $t$ tests between control and increases in oxygen consumption show that there are significant decreases in PCr/ATP and increases in calculated ADP $(P<0.001)$ with every step up. The relationships between $\mathrm{PCr} / \mathrm{ATP}$ and $\mathrm{MV}_{\mathrm{O}_{2}}$, and relative ADP and $\mathrm{MV}_{\mathrm{O}_{2}}$ are shown graphically in Fig. 4. This graph presents data where net increases in $\mathrm{MV}_{\mathrm{O}_{2}}$ were recorded. Linear regression analysis illustrates the downward trend of $\mathrm{PCr} / \mathrm{ATP}$ with increases in $\mathrm{MV}_{\mathrm{O}_{2}}$ (slope $=0.07, r$ $=0.63$ ). The mean maximum increase in calculated ADP was $80 \pm 16 \%$. This value is important for comparison with published models of ADP regulation of mitochondrial respiration in the heart.

Despite significant changes in ADP with increases in $\mathrm{MV}_{\mathrm{O}_{2}}$, there were no consistent changes in intracellular $\mathrm{pH}$, as estimated from the chemical shift of $P_{i}$. Likewise, there were no significant changes in free $\mathrm{Mg}^{2+}$ levels estimated from the 

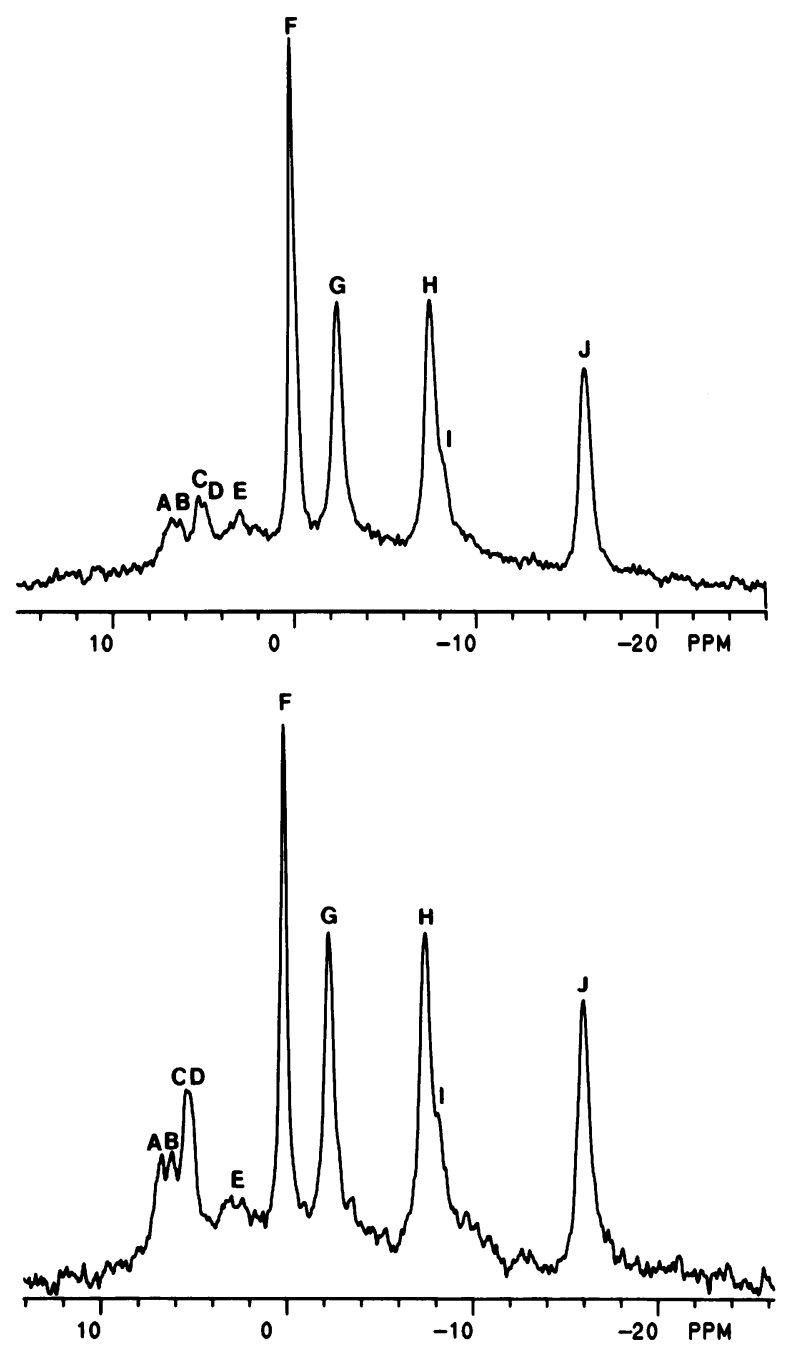

Figure 1. $(A){ }^{31} \mathrm{P}$ NMR spectrum of a sheep left ventricle (age $68 \mathrm{~d}$ ) in vivo. The spectrum represents the sum of 240 acquisitions obtained within $8 \mathrm{~min}$. 10- $\mathrm{Hz}$ line broadening was applied before Fourier transformation. Peak assignments are: phosphomonoesters (peak $A$ at $6.74 \mathrm{ppm}$, and $B$ at $6.27 \mathrm{ppm})$, extracellular $P_{\mathrm{i}}(\mathrm{C}$ at $5.23 \mathrm{ppm})$, intracellular $P_{i}(D$ at $4.90 \mathrm{ppm})$, phosphodiesters ( $E$ at $2.94 \mathrm{ppm}$ ), phosphocreatine (F at $0.0 \mathrm{ppm}$ ), $\gamma$-ATP (G at $-2.48 \mathrm{ppm}$ ), $\alpha$-ATP ( $\mathrm{H}$ at $-7.55 \mathrm{ppm}$ ), NAD (I at $-8.12 \mathrm{ppm}$ ), and $\beta$-ATP (J at -16.05 ppm). (B) A spectrum obtained from a newborn lamb (age $6 \mathrm{~d}$ ). As in $A$, this spectrum represents the sum of 240 acquisitions obtained in $8 \mathrm{~min}$ and with $10 \mathrm{~Hz}$ line broadening. Peak assignments are: phosphomonoesters (peak A at $6.64 \mathrm{ppm}$ ), phosphomonoesters and 2,3 DPG (peak B at $6.10 \mathrm{ppm}$ ), a combination of extracellular $P_{i}, 2,3$ DPG, and intracellular $P_{i}$ (peaks $C$ at $5.29 \mathrm{ppm}$ and $D$ at $5.00 \mathrm{ppm}$ ), phosphodiesters (E at $2.80 \mathrm{ppm}$ ), phosphocreatine (F at $0.0 \mathrm{ppm}$ ), $\gamma$-ATP (G at $-2.38 \mathrm{ppm}$ ), $\alpha$-ATP (H at $-7.53 \mathrm{ppm}$ ), NAD (I at $-8.27 \mathrm{ppm})$, and $\beta$-ATP $(\mathrm{J}$ at $-16.02 \mathrm{ppm})$. Note the increased relative areas of the phosphomonoester and $P_{i}$ peaks, and the decreased resolution between $C$ and $D$. This is partially due to the contribution of 2,3 DPG to these regions, which does not occur in the mature sheep (see text).

difference between the alpha and beta phosphate resonances. The chemical shift difference under control conditions was $8.50 \pm 0.06 \mathrm{ppm}$. This corresponds to a free $\mathrm{Mg}^{2+}$ concentration in the millimolar range $(0.8-2 \mathrm{mM})$ depending on the actual $K_{\mathrm{d}}$ of ATP for $\mathrm{Mg}^{2+}(27)$. These values are similar to the value reported in recent adult canine experiments (30a). This

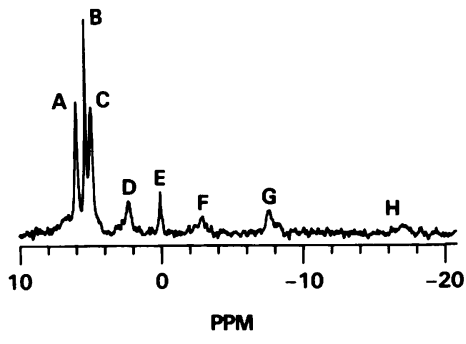

Figure 2. ${ }^{31} \mathrm{P}$ NMR spectrum of newborn lamb blood $(7 \mathrm{~d})$ at $38^{\circ} \mathrm{C}, \mathrm{pH}$ 7.4, and equilibrated with 95\% $\mathrm{O}_{2}$ and $5 \% \mathrm{CO}_{2}$. Data were acquired using a $90^{\circ}$ magnetization flip angle and a 16-s interpulse delay. This spectrum is the average of 60 scans with $8 \mathrm{~Hz}$

line broadening. Peak assignments are 2,3 DPG (A at $5.93 \mathrm{ppm}$ and $C$ at $4.86 \mathrm{ppm}$ ), extracellular $\mathrm{P}_{\mathrm{i}}$ (B at $\left.5.25 \mathrm{ppm}\right)$, which occurs in serum concentrations of $7.9 \pm 0.29 \mathrm{mM} / \mathrm{liter}$, phosphodiester (D at $2.51 \mathrm{ppm}$ ), exogenously added $\mathrm{PCr}$ (E at $0.0 \mathrm{ppm}), \gamma-\mathrm{ATP}$ (F at $-2.46 \mathrm{ppm}$ ), $\alpha$-ATP (G at $-7.55 \mathrm{ppm}$ ), and $\beta$-ATP (H at -16.00 ppm). Intracellular $P_{i}$ was not observed but was likely present under peak C. No 2,3 DPG peaks were observed in lamb plasma or in blood from adult sheep of the age used in this study.

result confirms data suggesting that changing $\mathrm{Mg}^{2+}$ is not an important factor in the calculation of ADP from the creatine kinase equilibrium reaction.

Analysis of change in intracellular $P_{i}$ with increases in cardiac work was complicated by the contribution of 2,3 DPG to the newborn heart spectrum. Calculated changes in $P_{i}$ are examined in the Discussion.

Effect of epinephrine infusion in mature sheep. Table IV summarizes data obtained with epinephrine infusion in six mature animals. The ${ }^{31} \mathrm{P}$ NMR spectra from a representative experiment in a mature sheep are shown in Fig. 5. The mean maximum increase in $\mathrm{MV}_{\mathrm{O}_{2}}(350 \%$ of baseline \pm 66$)$ was greater than that obtained in the newborns but the difference did not reach statistical significance by the unpaired $t$ test $(P$ $=0.07$ ). There was also no significant change in oxygen extraction in this group.

Even though there were large changes in $\mathrm{MV}_{\mathrm{O}_{2}}$ in the mature group of sheep with epinephrine, paired $t$ test analysis showed that there was no significant change in PCr/ATP, or $\mathrm{ADP}$ at the maximum $\mathrm{MV}_{\mathrm{O}_{2}}$ reached. These data are illustrated in Fig. 6 with similar format as Fig. 4. Although there was a low correlation coefficient for PCr/ATP vs. $\mathrm{MV}_{\mathrm{O}_{2}}, t$ test comparison of the slope with the slope from the newborn group shows a significant difference $(P<0.025)$.

Scatter was greatest for the $P_{i}$ measurements. This was because of the low concentration of $P_{i}$ in vivo resulting in a lower

Table II. Results of Experiments in Two Control Lambs

\begin{tabular}{crrrrr}
\hline Animal & Time & $\mathrm{CBF}$ & $\mathrm{MVO}_{2}$ & $\mathrm{PCr} / \mathrm{ATP}$ & $\mathrm{pH}_{\mathrm{i}}$ \\
\hline age & $\min$ & & & & \\
0105 & $2-10$ & 0.56 & 2.22 & 1.68 & 7.16 \\
$14 \mathrm{~d}$ & $32-40$ & 0.41 & 1.73 & 1.63 & 7.16 \\
0107 & $2-10$ & 0.46 & 2.18 & 1.58 & 7.12 \\
$7 \mathrm{~d}$ & $32-40$ & 0.46 & 2.24 & 1.62 & 7.13 \\
& & & & & \\
\hline
\end{tabular}

Two newborn lambs were monitored for a 40-min period without epinephrine infusion. Data from the last $8 \mathrm{~min}$ of the initial $10-\mathrm{min}$ period, and the final 10-min period are reported. Time, period of data collection from initial time 0 . 
Table III. Newborn Lamb Epinephrine Protocol Results

\begin{tabular}{|c|c|c|c|c|c|c|c|c|}
\hline Animal & Dose & RPP* & $\mathrm{CBF}^{\ddagger}$ & $\mathrm{MVO}_{2}^{8}$ & $\mathbf{P}_{\mathrm{i}}^{\prime \prime}$ & PCr/ATP & $\mathrm{pH}_{\mathrm{i}}$ & ADP' \\
\hline \multicolumn{9}{|l|}{ age } \\
\hline 0710 & 0 & 9,954 & 0.73 & 2.34 & $1.6^{* *}$ & 1.82 & 7.04 & 17 \\
\hline \multirow[t]{4}{*}{$5 \mathrm{~d}$} & 1 & 10,948 & 0.93 & 2.99 & 2.1 & 1.76 & 7.03 & 17 \\
\hline & 2 & 23,025 & 2.50 & 6.81 & 5.1 & 1.41 & 7.03 & 29 \\
\hline & 3 & 29,370 & 2.90 & 7.46 & 6.9 & 1.20 & 7.03 & 42 \\
\hline & 4 & 31,464 & 3.06 & 7.29 & 6.8 & 1.20 & 7.02 & 41 \\
\hline 0717 & 0 & 7,964 & 0.66 & 1.91 & $1.6^{* *}$ & 1.93 & 7.07 & 14 \\
\hline \multirow[t]{4}{*}{$12 \mathrm{~d}$} & 1 & 15,015 & 1.15 & 3.47 & 1.51 & 1.96 & 7.06 & 13 \\
\hline & 2 & 18,860 & 1.75 & 4.91 & 5.28 & 1.50 & 7.06 & 33 \\
\hline & 3 & 26,362 & 2.50 & 7.70 & 7.17 & 1.28 & 7.01 & 43 \\
\hline & 4 & 29,786 & 2.75 & 5.60 & 6.65 & 1.34 & 7.02 & 39 \\
\hline 1027 & 0 & 7,906 & 0.70 & 4.01 & $1.6^{* *}$ & 1.55 & 7.06 & 33 \\
\hline \multirow[t]{4}{*}{$5 \mathrm{~d}$} & 1 & 13,689 & 1.10 & 6.26 & 3.2 & 1.33 & 7.05 & 46 \\
\hline & 2 & 25,425 & 2.13 & 8.73 & 4.1 & 1.24 & 7.05 & 50 \\
\hline & 3 & 28,875 & 1.67 & 3.96 & 3.7 & 1.26 & 7.06 & 50 \\
\hline & $\mathbf{R}$ & 6,273 & 0.40 & 2.00 & 2.5 & 1.63 & 7.07 & 24 \\
\hline 1103 & 0 & 9,950 & 0.75 & 2.05 & $1.6^{* *}$ & 1.65 & 7.05 & 25 \\
\hline \multirow[t]{5}{*}{$9 d$} & 1 & 18,145 & 1.50 & 6.09 & 3.4 & 1.44 & 7.06 & 35 \\
\hline & 2 & 17,928 & 1.64 & 6.59 & 3.6 & 1.42 & 7.09 & 39 \\
\hline & 3 & 17,280 & 1.75 & 4.29 & 2.0 & 1.40 & 7.09 & 40 \\
\hline & 4 & 20,740 & 1.75 & 5.64 & 1.9 & 1.62 & 7.05 & 26 \\
\hline & $\mathbf{R}$ & 8,775 & 0.86 & 3.15 & 1.9 & 1.62 & 7.03 & 26 \\
\hline 1110 & 0 & 11,590 & 0.57 & 2.05 & $1.6^{* *}$ & 1.64 & 7.07 & 27 \\
\hline \multirow[t]{5}{*}{$12 \mathrm{~d}$} & 1 & 20,600 & 1.17 & 3.19 & 2.7 & 1.51 & 7.06 & 31 \\
\hline & 2 & 26,000 & 1.50 & 5.98 & 3.5 & 1.42 & 7.06 & 33 \\
\hline & 3 & 25,298 & 1.67 & 6.37 & 3.5 & 1.41 & 7.03 & 31 \\
\hline & 4 & 29,040 & 1.89 & 5.85 & 4.2 & 1.33 & 7.03 & 34 \\
\hline & $\mathbf{R}$ & 10,400 & 0.83 & 2.50 & 1.2 & 1.69 & 7.06 & 21 \\
\hline 1120 & 0 & 7,344 & 0.39 & 1.32 & $1.6^{* *}$ & 1.44 & 7.13 & 45 \\
\hline \multirow[t]{5}{*}{$6 d$} & 1 & 15,680 & 1.04 & 4.32 & 4.0 & 1.16 & 7.13 & 62 \\
\hline & 2 & 24,500 & 1.50 & 6.12 & 4.7 & 1.08 & 7.12 & 68 \\
\hline & 3 & 26,790 & 1.61 & 6.55 & 4.1 & 1.15 & 7.09 & 60 \\
\hline & 4 & 34,650 & 2.25 & 6.83 & 4.7 & 1.08 & 7.09 & 62 \\
\hline & $\mathbf{R}$ & 7,774 & 0.54 & 2.08 & 1.3 & 1.78 & 7.13 & 19 \\
\hline 0301 & 0 & 5,610 & 0.36 & 2.00 & $1.6^{* *}$ & 1.78 & 7.03 & 18 \\
\hline \multirow[t]{4}{*}{$7 \mathrm{~d}$} & 1 & 15,604 & 1.14 & 4.43 & 3.7 & 1.54 & 7.03 & 31 \\
\hline & 2 & 14,861 & 1.09 & 5.40 & 2.6 & 1.66 & 6.97 & 21 \\
\hline & 4 & 16,082 & 1.46 & 6.13 & 3.1 & 1.60 & 7.03 & 30 \\
\hline & $\mathbf{R}$ & 5,536 & 0.64 & 2.68 & 1.1 & 1.84 & 7.03 & 16 \\
\hline 0308 & 0 & 10,800 & 0.79 & 1.95 & $1.6^{* *}$ & 1.50 & 7.16 & 43 \\
\hline \multirow[t]{4}{*}{$7 d$} & 1 & 14,014 & 1.05 & 2.67 & 1.3 & 1.54 & 7.16 & 40 \\
\hline & 2 & 17,595 & 1.36 & 3.50 & 3.6 & 1.27 & 7.15 & 60 \\
\hline & 3 & 21,150 & 1.41 & 3.69 & 3.7 & 1.26 & 7.15 & 63 \\
\hline & $\mathbf{R}$ & 8,272 & 0.97 & 2.39 & 0.5 & 1.63 & 7.16 & 36 \\
\hline
\end{tabular}

After an initial 10-min baseline period, eight newborn lambs underwent 10 min graded infusions of epinephrine $($ dose $=$ micrograms $/$ minute per kilogram). The recovery period $(R)$ represents the final $10 \mathrm{~min}$ of a 40 -min period in which the epinephrine was decreased to the lowest tolerated dose. All NMR data were corrected for differential saturation.

* RPP, mean arterial pressure (millimeters of mercury) $\times$ heart rate (beats per minute).

$\$$ Coronary blood flow in milliliters per minute per gram wet wt.

${ }^{-} \mathrm{MVO}_{2}$ is expressed as micromoles/minute per gram left ventricular wet weight.

" $P_{i}$ was calculated as described in Discussion.

'ADP was calculated as described in Methods.

** Baseline $P_{i}$ value is assumed as described in Discussion.

signal to noise for the area of $\mathrm{P}_{\mathrm{i}}$ when compared with the areas of $\mathrm{PCr}$ and ATP. An additional problem was the frequent lack of resolution between intra and extracellular $P_{i}$. By estimating from the control $P_{i} / A T P$ and using [ATP] from the freeze extraction experiments, the baseline level of intracellular $P_{i}$ was $1.60 \pm 0.32 \mathrm{mmol} /$ liter cell water. There was no significant increase in $\mathrm{P}_{\mathrm{i}}$ with each change in $\mathrm{MV}_{\mathrm{O}_{2}}$ as determined by paired $t$ test.
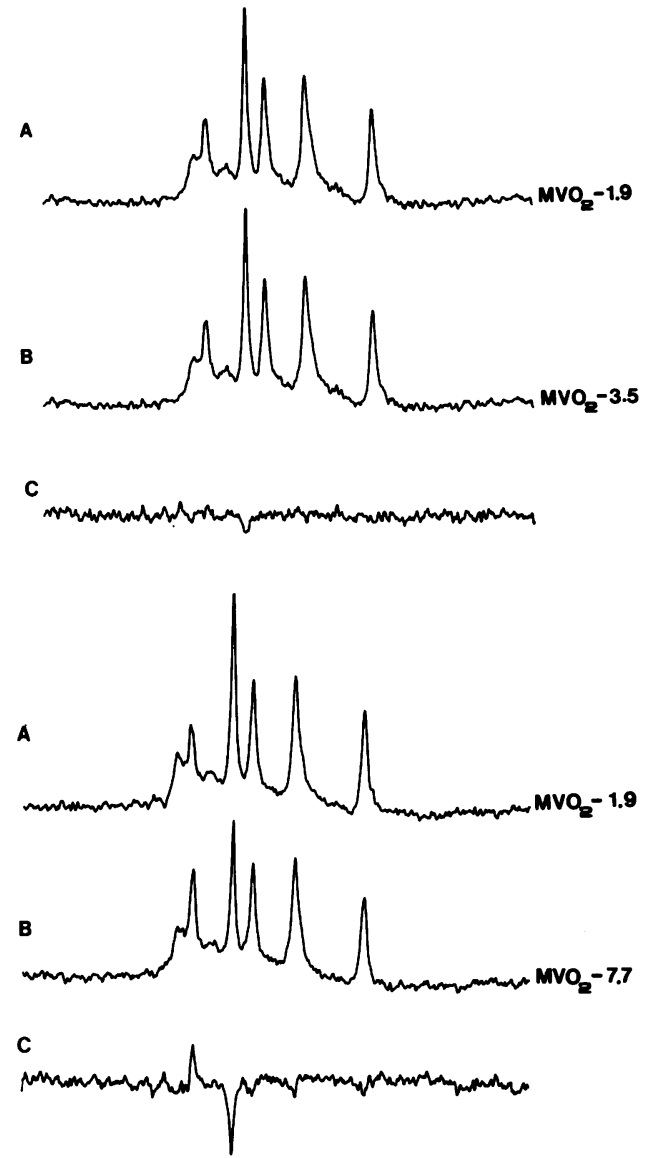

Figure 3. (Top) Example of the effect of an infusion of $1 \mu \mathrm{g} / \mathrm{kg}$ per min of epinephrine in a newborn lamb. Spectra were obtained as described in Methods. Peak assignments are as presented in Figs. 1 and 2. (A) Baseline spectrum obtained while measured $\mathrm{MV}_{\mathrm{O}_{2}}$ was 1.9 $\mu \mathrm{g} / \mathrm{kg}$ per min. (B) Spectrum obtained during the epinephrine infusion. $\mathrm{MV}_{\mathrm{O}_{2}}$ increased to $3.5 \mu \mathrm{mol} / \mathrm{g}$ per min. $(C)$ Difference between spectra $B$ and $A$. (Bottom) The effect of further increasing the epinephrine to $3 \mu \mathrm{g} / \mathrm{kg}$ per min. $(A)$ Baseline spectrum is the same as $A$ in the top panel. $(B)$ Spectrum obtained during the increased epinephrine dose. $\mathrm{MV}_{\mathrm{O}_{2}}$ was $7.7 \mu \mathrm{mol} / \mathrm{g}$ per min. $(C)$ Difference between spectra $B$ and $A$.

\section{Discussion}

Analysis of $P_{i}$ in newborns. Although the Lorentzian line fitting allows quantification of overlapping resonant peaks, adequate resolution between peaks is still necessary to accurately calculate areas. This causes some difficulties in attempting to quantitate $P_{i}$ in newborn lamb hearts. The application of $2-5-\mathrm{Hz}$ line broadening permits detection of the position of the $P_{i}$ peak for $\mathrm{pH}$ determination with high precision, but sufficient signal to noise and resolution for reliable peak area quantitation is difficult because of the overlapping 2,3 DPG peak (Fig. 2). The detected 2,3 DPG is from the blood perfusing the myocardium and present in the ventricular chamber (20). This is not a problem in older lambs because 2,3 DPG levels drop to near undetectable levels after the second week of life (31).

Evaluation of difference spectra from the newborn epinephrine protocol shows increases in only one peak near the chemical shift (4.9-5.0 ppm) of intracellular $P_{i}$ (Fig. 3) with increases in $\mathrm{MV}_{\mathrm{O}_{2}}$. This is consistent with an increase in intracellular $P_{i}$, as changes in 2,3 DPG would result in two peaks, at 

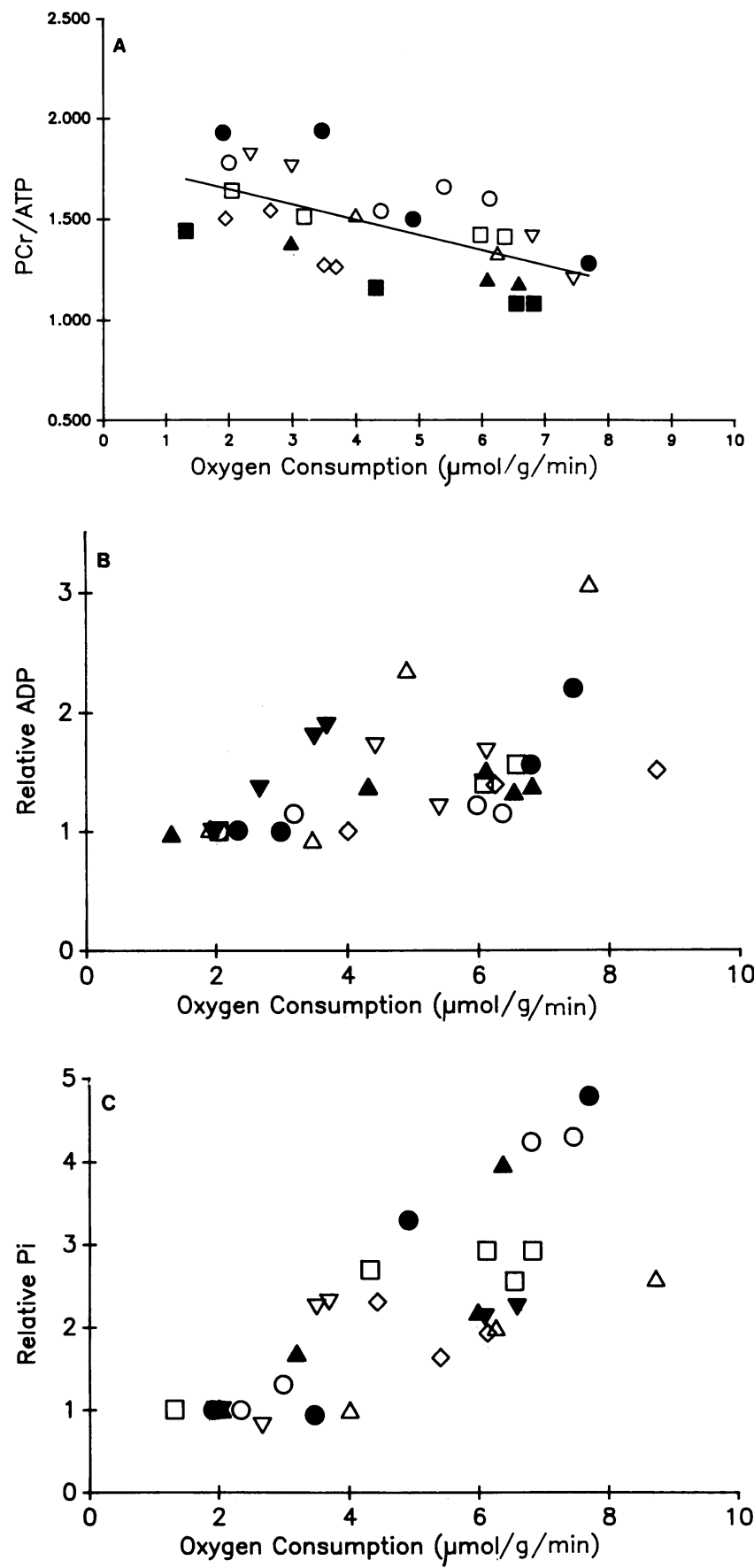

Figure 4. (A) PCr/ATP plotted as a function of $\mathrm{MV}_{\mathrm{O}_{2}}$ from the epinephrine protocol in eight newborn lambs. Data points from increases in $\mathrm{MV}_{\mathrm{O}_{2}}$ only are plotted. Each symbol represents the results from one animal. Linear regression analysis yields a line equation of $\mathrm{PCr} / \mathrm{ATP}=1.79-0.07 \mathrm{MV}_{\mathrm{O}_{2}}(r=0.63)$. (B) Relative ADP vs. $\mathrm{MV}_{\mathrm{O}_{2}}$ from eight newborn lambs. $(C)$ Relative $\mathrm{P}_{\mathrm{i}}$ vs. $\mathrm{MV}_{\mathrm{O}_{2}}$ from eight newborn lambs.

4.9 and $5.9 \mathrm{ppm}$ (see reference 20). Calculation of the absolute $P_{i}$ concentrations requires the assumption that the baseline levels approximate those in mature animals i.e., $1.6 \mathrm{mM} /$ liter cell water, since no baseline concentrations of $P_{i}$ are available. Using this approach, the changes in $P_{i}$ during the work jumps in the lambs were calculated using the $P_{i}$ peak areas of the difference spectra normalized to the control ATP. It was also interesting to note that the magnitude of $P_{i}$ increase equaled

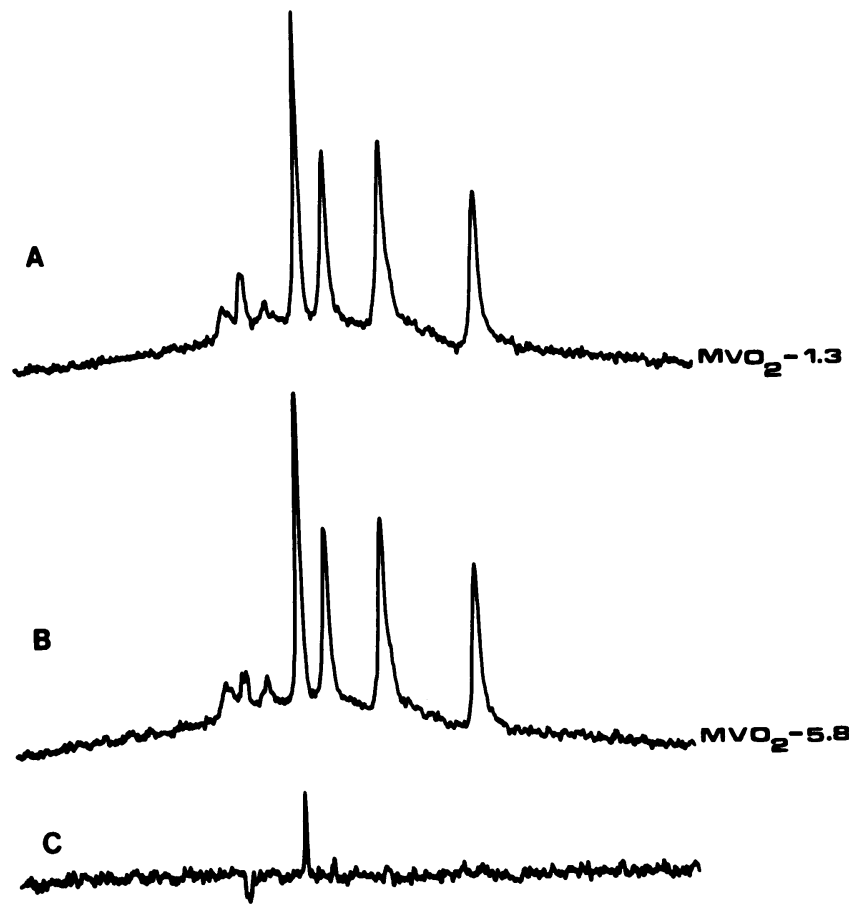

Figure 5. ${ }^{31} \mathrm{P}$ NMR spectra from an epinephrine experiment in a mature sheep. $(A)$ Baseline spectrum obtained while the measured $\mathrm{MV}_{\mathrm{O}_{2}}$ was $1.3 \mu \mathrm{g} / \mathrm{kg}$ per min. (B) Spectrum obtained during epinephrine infusion of $2 \mu \mathrm{g} / \mathrm{kg}$ per min, which increased $\mathrm{MV}_{\mathrm{O}_{2}}$ to $5.8 \mu \mathrm{mol} / \mathrm{g}$ per min. (C) Difference between $\mathrm{B}$ and $\mathrm{A}$. Note that in contrast to Fig. 3 , there is an increase in $\mathrm{PCr}$ and a decrease in $\mathrm{P}_{\mathrm{i}}$ in this particular animal. For the adult animals overall, no significant change in phosphates were observed over the workloads studied.

the area of $\mathrm{PCr}$ decrease $\left(\Delta \mathrm{P}_{\mathrm{i}} / \Delta \mathrm{PCr}=0.94 \pm 0.14\right)$ as has been described in skeletal muscle studies (32). The relationship of changes in $\mathrm{P}_{\mathrm{i}}$ with increases in $\mathrm{MV}_{\mathrm{O}_{2}}$ is shown in Fig. $4 C$. There is a significant increase in $\mathrm{P}_{\mathrm{i}}(P<0.001)$ as $\mathrm{MV}_{\mathrm{O}_{2}}$ increases. Comparison of the slope from this graph with that in Fig. $6 C$ shows that with increasing $\mathrm{MV}_{\mathrm{O}_{2}}, \mathrm{P}_{\mathrm{i}}$ changes much more in newborns than in mature animals. The mean maximal increase in $P_{i}$ was $200 \pm 32 \%$. If baseline values were underestimated, then the degree of change would be exaggerated. However, analysis of the total area of the combined 2,3 DPG and $P_{i}$ peak shows that at most this would be an underestimate of $40-50 \%$ if the DPG contribution were considered negligible. This would still allow a substantially larger change in $P_{i}$ with increased $\mathrm{MV}_{\mathrm{O}_{2}}$ for newborns than adults.

Regulation of myocardial respiration in the developing animal. In these studies we found that in newborn lambs, the ATP hydrolysis products, ADP and $P_{i}$, as well as $\mathrm{PCr}$, changed in appropriate directions to explain an increase in $\mathrm{MV}_{\mathrm{O}_{2}}$. However, in the adult sheep heart, we found no significant changes in these metabolites using an identical protocol. These results suggest that there are potential alterations in the regulation of myocardial respiration as a function of development. The ATP hydrolysis products appear to be more prominent in regulation of the newborn heart than of the adult, although the baseline concentrations of these metabolites are similar. It is possible that some of the differences between the two groups may be a result of a differential response to the stress of surgery and anesthesia. The ability to reverse changes in $\mathrm{P}_{\mathrm{i}}$ and $\mathrm{PCr} /$ ATP with reduction of epinephrine supports the contention 

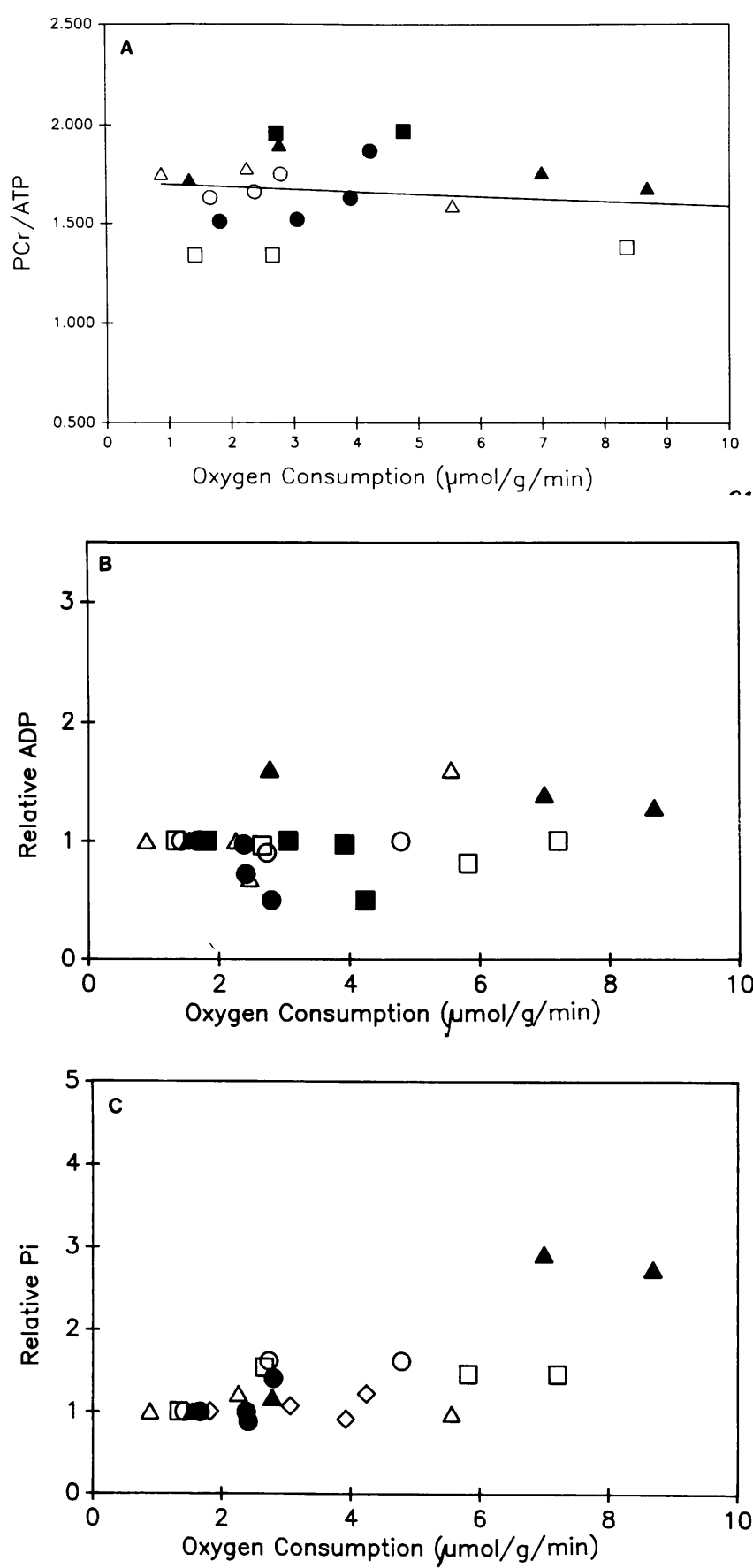

Figure 6. (A) PCr/ATP plotted as a function of $\mathrm{MV}_{\mathrm{O}_{2}}$ from epinephrine protocol in six mature sheep. Each symbol represents the results from one animal. Linear regression analysis yields a line with equation $\mathrm{PCr} / \mathrm{ATP}=1.67-0.01 \mathrm{MV}_{\mathrm{O}_{2}}(r=0.19)$. (B) Relative ADP vs. $\mathrm{MV}_{\mathrm{O}_{2}}$ for six mature sheep. $(C)$ Relative $\mathrm{P}_{\mathrm{i}}$ vs. $\mathrm{MV}_{\mathrm{O}_{2}}$ for six mature sheep.

that these animals were not irreversibly compromised by these procedures. Additional support is provided by the lack of change in the phosphate metabolites after surgery in the twotime control animals.

If $\mathrm{ADP}$ and $\mathrm{P}_{\mathrm{i}}$ are the major factors regulating mitochondrial respiration in the newborn, then there must be other operational control factors in the adult. As respiratory efficiency and activity of the cytochrome chain appear to be similar in the newborn and adult (14), then it is likely that there are
Table IV. Epinephrine Protocol in Mature Animals

\begin{tabular}{|c|c|c|c|c|c|c|c|c|}
\hline Animal & Dose & RPP* & $\mathrm{CBF}^{\ddagger}$ & $\mathrm{MVO}_{2}{ }^{\S}$ & $P_{i}^{\prime \prime}$ & $\mathrm{PCr} / \mathrm{ATP}$ & $\mathrm{pH}_{\mathrm{i}}$ & ADP' \\
\hline \multicolumn{9}{|l|}{ age } \\
\hline 0701 & 0 & 7,866 & 0.50 & 1.42 & 1.80 & 1.97 & 7.01 & 11 \\
\hline \multirow[t]{6}{*}{$26 \mathrm{~d}$} & 1 & 13,845 & 1.00 & 2.73 & 2.92 & 1.97 & 7.01 & 10 \\
\hline & 2 & 20,230 & 1.75 & 4.78 & 2.92 & 1.96 & 7.01 & 11 \\
\hline & 3 & 20,586 & 1.78 & 4.50 & 2.75 & 1.90 & 7.01 & 13 \\
\hline & 4 & 20,437 & 1.65 & 4.44 & 2.75 & 1.88 & 7.09 & 16 \\
\hline & 8 & 19,728 & 1.62 & 3.55 & 2.70 & 1.88 & 7.04 & 15 \\
\hline & $\mathbf{R}$ & 7,755 & 0.60 & 1.03 & 1.75 & 2.11 & 7.04 & 8 \\
\hline 1202 & 0 & 5,700 & 0.40 & 1.67 & 1.46 & 1.63 & 7.18 & 36 \\
\hline \multirow[t]{3}{*}{$68 \mathrm{~d}$} & 1 & 9,114 & 0.59 & 2.38 & 1.46 & 1.66 & 7.18 & 35 \\
\hline & 2 & 9,280 & 0.56 & 2.41 & 1.29 & 1.73 & 7.16 & 26 \\
\hline & 3 & 13,450 & 0.63 & 2.80 & 2.06 & 1.75 & 7.12 & 18 \\
\hline 0128 & 0 & 5,700 & 0.35 & 0.89 & 3.10 & 1.75 & 7.13 & 25 \\
\hline \multirow[t]{5}{*}{$56 \mathrm{~d}$} & 1 & 11,880 & 0.89 & 2.26 & 3.78 & 1.78 & 7.18 & 25 \\
\hline & 2 & 17,380 & 0.78 & 2.14 & 3.01 & 1.87 & 7.10 & 17 \\
\hline & 4 & 24,012 & 1.07 & 2.41 & 3.01 & 1.56 & 7.18 & 40 \\
\hline & 8 & 30,750 & 2.07 & 5.56 & 3.05 & 1.58 & 7.18 & 38 \\
\hline & $\mathbf{R}$ & 5,474 & 0.78 & 1.31 & 3.10 & 2.36 & 7.18 & 1 \\
\hline 0205 & 0 & 10,354 & 0.33 & 1.55 & 1.03 & 1.90 & 7.14 & 18 \\
\hline \multirow[t]{4}{*}{$62 d$} & 1 & 15,525 & 0.67 & 2.78 & 1.20 & 1.76 & 7.10 & 29 \\
\hline & 4 & 35,076 & 1.39 & 7.00 & 3.01 & 1.68 & 7.08 & 25 \\
\hline & 8 & 36,504 & 1.52 & 8.69 & 2.83 & 1.72 & 7.06 & 23 \\
\hline & $\mathbf{R}$ & 5,504 & 0.36 & 2.31 & 2.23 & 2.42 & 7.16 & 1 \\
\hline 0128 & 0 & 6,313 & 0.44 & 1.34 & 1.12 & 1.34 & 7.05 & 45 \\
\hline \multirow[t]{4}{*}{$65 \mathrm{~d}$} & 1 & 12,700 & 0.70 & 2.66 & 1.72 & 1.38 & 7.04 & 43 \\
\hline & 4 & 21,140 & 1.36 & 5.82 & 1.63 & 1.44 & 7.02 & 35 \\
\hline & 8 & 31,620 & 1.94 & 7.21 & 1.63 & 1.34 & 7.03 & 45 \\
\hline & $\mathbf{R}$ & 5,980 & 0.68 & 2.43 & 0.69 & 1.58 & 7.05 & 29 \\
\hline 0310 & 0 & 6,160 & 0.53 & 1.82 & 1.12 & 1.51 & 7.06 & 34 \\
\hline \multirow[t]{5}{*}{$60 d$} & 1 & 9,360 & 0.98 & 3.06 & 1.20 & 1.52 & 7.06 & 34 \\
\hline & 2 & 11,856 & 1.06 & 3.92 & 1.02 & 1.63 & 7.14 & 33 \\
\hline & 4 & 17,632 & 1.18 & 3.72 & 1.34 & 1.65 & 7.12 & 27 \\
\hline & 8 & 25,437 & 1.73 & 4.24 & 1.37 & 1.87 & 7.12 & 17 \\
\hline & $\mathbf{R}$ & 5,504 & 0.70 & 1.68 & 0.45 & 2.11 & 7.13 & 10 \\
\hline
\end{tabular}

Six mature sheep underwent a protocol similar to that outlined for the newborn lambs in Table III.

differences in intermediary metabolism before oxidative phosphorylation or in the regulatory mechanisms in the cytochrome chain. Although the field remains controversial, there are several other focal areas under consideration as possible factors influencing myocardial respiration in vivo. Among these are coronary blood flow (13), the creatine kinase equilibrium reaction (12), and the NADH redox state (8).

The rates of coronary blood flow and oxygen delivery have been considered as a regulators of myocardial oxygen consumption. In this study, no significant increases in oxygen extraction were found with large $\mathrm{MV}_{\mathrm{O}_{2}}$ increases from either age group, leaving coronary blood flow as the primary determinant of oxygen supply to the heart. There was no significant difference in the maximum coronary blood flow per gram between the newborns and the mature sheep. Therefore, it is unlikely that any developmental changes in myocardial flow reserve account for differences in regulation of myocardial respiration between the two groups. Because we are measuring global and not regional left ventricular blood flow, there could be undetected differences in redistribution of coronary blood flow during stress, leaving some areas of the myocardium relatively ischemic in the newborns and resulting in the observed changes in the phosphate metabolites. NMR measurements could be a summation of extremes from different portions of the myocardium. However, the lack of significant changes in 
intracellular $\mathrm{pH}$ despite changes in $\mathrm{PCr} / \mathrm{ATP}$ and $\mathrm{P}_{\mathrm{i}}$ provides some evidence against local ischemia as a cause of these changes. Studies of transmural myocardial blood flow distribution in lambs stressed by catecholamine infusion have not been performed. However, the distribution of blood flow within the left ventricle has been shown to be similar in resting, unanesthetized newborns and mature sheep (33). Also, it has been demonstrated that, the neonatal lamb can maintain the ratio of subepicardial to subendocardial blood flow with increases in $\mathrm{MV}_{\mathrm{O}_{2}}$ during hypoxic stress (34). It is thus unlikely that changes in $\mathrm{PCr}$ are due to relative ischemia in portions of the myocardium.

The significance of the creatine kinase $(\mathrm{CK})$ reaction and the existence of the creatine-creatine phosphate shuttle have long been subjects of debate. Bessman (35) and Jacobus (36) have recently reviewed this subject. There are changes in the concentration and profile of the creatine kinase isozymes with maturation, which may affect mechanisms of mitochondrial regulation. Ingwall et al. have shown that in the few weeks before birth, there is a substantial increase in the concentration of $\mathrm{MM}-\mathrm{CK}$ and mitochondrial-CK and in the relative proportion of mitochondrial-CK (3). These changes are accompanied by substantial increases in the total creatine pool. After birth, there is a continued increase in total $\mathrm{CK}$, whereas the relative concentrations and the creatine pool hold constant. Creatine kinase has been proposed to facilitate the diffusion of ADP from the myofibrils and ATP from the mitochondria (37). Conversion of ADP to creatine theoretically creates an alternative pathway for diffusion (37). Lower creatine kinase concentrations such as those that occur in the fetus and neonate might limit access to this second pathway, thereby slowing the rate of ADP delivery to the mitochondria. This may result in an increase in cytosolic ADP with increases in work due to hampered diffusion through the neonatal cytoplasm.

Several studies in perfused hearts have focused on the importance of the mitochondrial NADH redox state as a regulator of myocardial respiration $(8,38)$. Using glucose as a substrate, increases in the NADH redox state accompanied increases in oxygen consumption, whereas there was no simultaneous change in ADP or $\mathrm{P}_{\mathrm{i}}(8)$. However, this effect is substrate dependent $(8,9,38)$. The importance of the ATP hydrolysis products has been shown to increase with the use of pyruvate as substrate and with the blocking of pyruvate dehydrogenase (38). Therefore, alterations in intermediary substrate metabolism and the NADH redox state may be responsible for differences in regulation between the newborn and the mature sheep.

Developmental differences of substrate metabolism have been shown to exist in several species, including sheep $(4,5$, $15,39,40)$. The primary myocardial energy substrates during fetal and early postnatal life appear to be carbohydrate and/or lactate $(4,5)$. Although it is species dependent, fatty acid oxidation by fetal and newborn mitochondria has been shown to be limited by deficits or immaturities in carnitine and acylcarnitine transferases $(15,39,40)$. Additionally, in fetal sheep, plasma FFA concentration is low, possibly limited by placental permeability (41). Concurrent with postnatal increase in circulating FFA, there is a decrease in myocardial uptake of lactate $(4,5,41)$. Therefore, the newborn lambs used in this study would be in the state of transition from a carbohydrate based metabolism to one based on FFA. The differences in intermediary metabolism between the neonate and the adult may be responsible for the observed changes in the relation of phosphate metabolites with work transitions.

The relationship between the ATP hydrolysis products and $\mathrm{MV}_{\mathrm{O}_{2}}$ has been extensively investigated in the adult canine myocardium $(10,30 \mathrm{a})$. In those studies, no changes in ADP or $\mathrm{P}_{\mathrm{i}}$ occurred with moderate $\left(\sim 3\right.$-fold) increases in $\mathrm{MV}_{\mathrm{O}_{2}}$ induced by pacing or either epinephrine or phenylephrine infusion. Further analysis showed that a simple Michaelis-Menton model of respiration involving ADP and $P_{i}$ was inadequate to explain those results. The data and conclusions from those studies are consistent with the data from adult sheep in this study. The lack of correlation between ADP and $\mathrm{P}_{\mathrm{i}}$ levels with $\mathrm{MV}_{\mathrm{O}_{2}}$ is not species specific and may represent a fundamental property of adult myocardium. However, large changes in ADP and $\mathrm{P}_{\mathrm{i}}$ are associated with increases in $\mathrm{MV}_{\mathrm{O}_{2}}$ in the newborn. This response is similar to that found in skeletal muscle $(32,42)$. The magnitude of the change approaches that predicted from the Michaelis-Menton model. This suggests that ADP and $P_{i}$ may play a more prominent role in regulation of respiration in the newborn heart than the adult. In contrast, a mechanism of respiratory regulation seems to be operational in the adult myocardium, which is either not present or relatively unimportant in the newborn.

In summary, this study demonstrates that there are significant differences in the response of myocardial phosphate metabolites to increases in work and $\mathrm{MV}_{\mathrm{O}_{2}}$ between newborns and adults of the same species. These data suggest that the mechanism of $\mathrm{MV}_{\mathrm{O}_{2}}$ regulation by work changes during postnatal development. These changes in this basic property of the heart may require special considerations in the treatment and maintenance of the developing heart.

\section{Acknowledgments}

We would like to thank Dr. Julie Swain, Surgery Branch National Heart, Lung, and Blood Institute and James Moore for their help in the early stages of this work.

Dr. Portman is a recipient of National Research Service Award HL-07411.

\section{References}

1. Friedman, W. F. 1972. The intrinsic physiologic properties of the developing heart. Prog. Cardiovasc. Dis. 15:87-111.

2. Goodwin, C. W., L. Mela, C. Deutsch, R. E. Forster, L. D. Miller, and M. Delivoria-Papadoppoulos. 1976. Development and adaptation of heart mitochondrial respiratory function in fetus and newborn. Adv. Exp. Med. Biol. 75:713-719.

3. Ingwall, J. S., M. F. Kramer, D. Woodman, and W. F. Friedman. 1981. Maturation of energy metabolism in the lamb: changes in myosin ATPase and creatine kinase activities. Pediatr. Res. 15:1128-1133.

4. Fisher, D. J., M. A. Heyman, and A. M. Rudolph. 1980. Myocardial oxygen and carbohydrate metabolism in fetal lambs in utero and adult sheep. Am. J. Physiol. 238:H399-H405.

5. Fisher, D. J., M. A. Heyman, and A. M. Rudolph. 1981. Myocardial oxygen consumption of oxygen and carbohydrates in newborn sheep. Pediatr. Res. 15:843-846.

6. Gibbs, C. 1985 . The cytoplasmic phosphorylation potential. Its possible role in the control of myocardial respiration and cardiac contractility. J. Mol. Cell. Cardiol. 17:727-731.

7. Hassinen, I. E. 1986. Mitochondrial respiratory control in the myocardium. Biochim. Biophys. Acta. 853:135-151.

8. Katz, L. A., A. P. Koretsky, and R. S. Balaban. 1987. A mechanism of respiratory control in the heart: a ${ }^{31} \mathrm{P}$ NMR and NADH study. FEBS (Fed. Eur. Biochem. Soc.) Lett. 221:270-276. 
9. Fromm, A. H. L., M. A. Petein, S. P. Michurski, S. D. Zimmer, and K. Ugurbil. 1986. ${ }^{31} \mathrm{P}-\mathrm{NMR}$ studies of respiratory regulation in the intact myocardium. FEBS (Fed. Eur. Biochem. Soc.) Lett. 206:257261.

10. Balaban, R. S., H. L. Kantor, L. A. Katz, and R. W. Briggs. 1986. Relation between work and phosphate metabolites in the in vivo paced mammalian heart. Science (Wash. DC). 232:1121-1123.

11. Balaban, R. S., A. P. Koretsky, and L. Katz. 1988. NMR investigations of cellular energy metabolism. Ann. NY Acad. Sci. 508:48-53.

12. Mela-Riker, L. M., and R. D. Bukowsi. 1985. Regulation of mitochondrial activity in cardiac cells. Annu. Rev. Physiol. 47:645663.

13. Feigl, E. O. 1983. Coronary physiology. Physiol. Rev. 63:1-205.

14. Wells, R. J., W. F. Friedman, and B. E. Sobel. 1972. Increased oxidative metabolism in the fetal and newborn lamb heart. Am. J. Physiol. 226:1488-1493.

15. Werner, J. C., V. Whitman, J. Musselman, and H. G. Schule. 1982. Perinatal changes in mitochondrial respiration of the rabbit. Biol. Neonate. 42:208-216.

16. Sordahl, W. A., C. A. Crow, G. H. Kraft, and A. Schwartz. 1972. Some ultrastructural and biochemical aspects of heart mitochondria associated with development: fetal and cardiomyopathic tissue. J. Mol. Cell. Cardiol. 4:1-10.

17. Warschau, J. B. 1969. Cellular energy metabolism during fetal development. I. Oxidative phosphorylation in the fetal heart. J. Cell Biol. 41:651-657.

18. Nicholls, D. G. 1982. Bioenergetics: An Introduction to the Chemiosmotic Theory. Academic Press, Inc., New York. 1-189.

19. Portman, M. A., F. W. Heineman, S. James, and R. S. Balaban. 1988. Simultaneous monitoring of coronary blood flow and ${ }^{31} \mathrm{P}$ NMR detected myocardial metabolites. Magn. Reson. Med. 7:243-247.

20. Katz, L. A., J. A. Swain, M. A. Portman, and R. S. Balaban. 1988. Intracellular $\mathrm{pH}$ and inorganic phosphate content of the heart in vivo. Am. J. Physiol. 255:H189-196.

21. Downing, S. E., J. C. Lee, J. F. Taylor, and K. Halloran. 1973. Influence of norepinephrine and digitalis on myocardial oxygen consumption in the newborn lamb. Circ. Res. 32:471-479.

22. Innes, I. R., and M. Nickerson. 1975. Norepinephrine, epinephrine, and the sympathomimetic amines. In The Pharmacological Basis of Therapeutics. L. S. Goodman and A. Gilman, editors. McMillan, New York. 477-513.

23. Juengling, E., and H. Kammermeier. 1980. Rapid assay of adenine nucleotides or creatine compounds in extracts of cardiac tissue by paired ion reverse phase high performance liquid chromatography. Anal. Biochem. 102:358-361.

24. Kantor, H. L., R. W. Briggs, K. R. Metz, and R. S. Balaban. 1986. Gated in vivo examination of cardiac metabolites with ${ }^{31} \mathrm{P}$ nuclear magnetic resonance. Am. J. Physiol. 251:H171-175.

25. Balaban, R. S. 1984. The application of nuclear magnetic resonance to the study of cellular physiology. Am. J. Physiol. 246:C10C19.

26. Lawson, J. W. R., and R. L. Veech. 1979. Effects of pH and free $\mathrm{Mg}++$ on the $\mathrm{Keq}$ of the creatine kinase equilibrium reaction and other phosphate hydrolyses and phosphate transfer reactions. J. Biol. Chem. 254:6528-6537.

27. Wu, S. T., G. M. Pieper, J. M. Salhany, and R. S. Eliot. 1984. Measurement of free magnesium in perfused and ischemic arrested heart muscle. A quantitative ${ }^{31} \mathrm{P}$ NMR and multiequilibrium analysis. Biochemistry. 20:7399-7403.

28. Wall, F. J. Statistical Data Analysis Handbook. 1986. McGraw-Hill Book Co., NY. 1-519.

29. Tofts, P., and S. Wray. 1985. Changes in brain phosphorous metabolites during the post-natal development of the rat. J. Physiol. (Lond.). 359:417-429.

30. Gyulai, L., L. Bolinger, J. S. Leigh, Jr., C. Barlow, and B. Chance. 1984. Phosphoryethanolamine-the major constituent of the phosphomonoester peak observed by ${ }^{31} \mathrm{P}$ NMR on developing dog brain. FEBS (Fed. Eur. Biochem. Soc.) Lett. 178:137-142.

30a. Katz, L. A., J. A. Swain, M. A. Portman, and R. S. Balaban. 1989. Relation between phosphate metabolites and oxygen consumption of heart in vivo. Am. J. Physiol. 256:H265-H274.

31. Lister, G., T. K. Walter, H. T. Versmold, P. R. Dallman, and A. M. Rudolph. 1979. Oxygen delivery in lambs: cardiovascular and hematologic development. Am. J. Physiol. 237:H668-H675.

32. Taylor, D. J., P. Styles, P. M. Matthews, D. A. Arnold, D. G. Gadian, P. Bore, and G. K. Radda. 1986. Energetics of human muscle: exercise induced ATP depletion. Magn. Reson. Med. 3:44-54.

33. Fisher, D. J., M. A. Heymann, and A. M. Rudolph. 1982. Regional and myocardial blood flow and oxygen delivery in fetal, newborn, and adult sheep. Am. J. Physiol. 243:H729-H731.

34. Fisher, D. J. 1984. Increased regional myocardial blood flow and oxygen deliveries during hypoxemia in lambs. Pediatr. Res. 18:602-606.

35. Bessman, S. P. 1986. The physiological significance of the creatine phosphate shuttle. Adv. Exp. Med. Biol. 194:1-11.

36. Jacobus, W. E. 1985. Respiratory control and the integration of heart high-energy phosphate metabolism by mitochondrial creatine kinase. Annu. Rev. Physiol. 47:707-725.

37. Meyer, R. A., H. L. Sweeney, and M. J. Kushmerick. 1982. A simple analysis of the "Phosphocreatine Shuttle". Am. J. Physiol. 242:1-11.

38. Katz, L. A., A. P. Koretsky, and R. S. Balaban. 1988. The activation of dehydrogenase activity and cardiac respiration: $A{ }^{31} \mathrm{P}$ NMR study. Am. J. Physiol. 255:H185-H188.

39. Wittels, B., and R. Bressler. 1963. Lipid metabolism in the newborn heart. J. Clin. Invest. 10:1639-1646.

40. Warshaw, J. B., and M. L. Terry. 1970. Cellular energy metabolism during fetal development. II. Fatty acid oxidation by the developing heart. J. Cell Biol. 44:354-360.

41. Van Duyne, C. M., H. R. Parker, R. J. Havel, and L. W. Holm. 1960. Free fatty acid metabolism in fetal and newborn sheep. Am. J. Physiol. 199:987-990.

42. Chance, B., J. S. Leigh, B. J. Clark, J. Maris, J. Kent, S. Nioka, and D. Smith. 1985. Control of oxidative metabolism and oxygen delivery in human skeletal muscle: a steady-state analysis of the work/ energy cost transfer function. Proc. Natl. Acad. Sci. USA. 82:83848388. 